\title{
FAMILIAL HAEMOPHAGOCYTIC RETICULOSIS
}

\author{
BY \\ JAMES W. FARQUHAR and ALBERT E. CLAIREAUX \\ From the Departments of Child Life and Health and Pathology, University of Edinburgh
}

(RECEIVED FOR PUBLICATION MAY 3, 1952)

A rare and invariably fatal condition, characterized by progressive erythropenia with or without depression of the circulating granulocytes and platelets despite a highly reactive marrow, has previously been described in adults. The liver, spleen and lymph nodes are enlarged, general intoxication is profound, and there may be a relapsing fever. The course seldom exceeds a few months, and terminally jaundice and purpura may appear. Such cases have been recorded by Scott and Robb-Smith (1939), Anderson (1944) and Asher (1946).

We have no desire to complicate further the nomenclature of the reticulo-endothelial system, but we do feel that the name histiocytic medullary reticulosis suggested for this condition by RobbSmith (1938), although aptly describing the cellular lesion in the lymph nodes, is less appropriate than haemophagocytic reticulosis when the whole disease process is considered. The latter not only indicates the system involved, but also the abnormal process and thus gives a lead to the clinical course the disease may pursue, whereas the names of other reticuloses are often eponymous or purely histological.

We have been unable to trace reports of such cases occurring in infants or children, unless those of Reese and Levy (1951) were in fact of haemophagocytic reticulosis, and wish to record two cases in siblings. The disease was rapidly fatal in both instances and in neither was a clinical diagnosis achieved before death.

\section{Case Reports}

Case 1. Robert, aged 9 weeks, was born to young and apparently healthy, unrelated, Gentile parents. Pregnancy had been normal and delivery was by forceps. The birth weight was $8 \mathrm{lb}$. $2 \mathrm{oz}$., and his condition satisfactory; he was breast-fed and thrived normally until 11 days before admission when he became apathetic, fretful and, within 48 hours, was febrile and vomiting. During the following week sickness, fever and listlessness persisted, the stools were a little loose and contained mucus, and the skin was oddly muddy or 'sunburnt '.
On admission the infant looked ill, he was febrile and had a café-au-lait pigmentation of the skin. The liver edge and the tip of the spleen were both palpable three fingerbreadths below the right and left costal margins, but lymph node enlargement was not noted. The Wassermann and Kahn tests were negative in parents and child, the urine was free from abnormal constituents and the stools were normally pigmented.

No infection could be detected clinically to explain the fever, and throat swabs, rectal swabs and a blood culture were negative. The blood cholesterol level was $125 \mathrm{mg} . \%$, the alkaline phosphatase $10 \mathrm{King}$ units and the thymol turbidity 2 units; the blood urea nitrogen was $9 \mathrm{mg} . \%$ while the total serum protein was $4 \cdot 2 \mathrm{~g} . \%$ with a normal albumin-globulin ratio. The peripheral blood on the day of admission showed a normochromic anaemia with a haemoglobin of $52 \%$ (Sahli), the haemoglobinometer having been checked by the photoelectric technique and found accurate to within $5 \%(100 \%=$ 13.8 g.\%). Stained blood films consistently showed a high percentage of 'smear' cells thought probably to be of lymphoid origin, but despite many careful attempts to prepare films in which the cells might be preserved for study, all were unsuccessful. Granulocytes were few, platelets deficient, and the bleeding time ranged from 16 to 27 minutes although the clotting time was normal. Fig. 1 records the progress of this case.

Red cell fragility was normal. Marrow was readily obtained by tibial puncture and showed: neutrophil polymorphs, $8 \%$; neutrophil metamyelocytes, $9 \%$; neutrophil myelocytes, $6 \%$; eosinophil polymorphs, $1 \%$; eosinophil metamyelocytes, $1 \%$; large lymphocytes, $12 \%$; small and intermediate lymphocytes, $52 \%$; monocytes, $3 \%$; 98 nucleated red cells per 100 white cells.

The infant's blood was Group $\mathrm{O} R \mathrm{R}$ negative with a negative Coombs test while the parents were $\mathrm{O} R \mathrm{Rh}$ positive. Radiological examination was reported as showing some periosteal elevation over both femora and humeri.

The illness ran a rapidly fatal course characterized by a remittent temperature resistant to massive doses of penicillin, progressive panhaematopenia with some nucleated red cells in the peripheral blood, and the terminal appearance of jaundice without any excess of urobilinogen in the urine. The hepatosplenomegaly persisted unchanged, and in the last few days fairly widespread skin bruising appeared. A small transfusion 


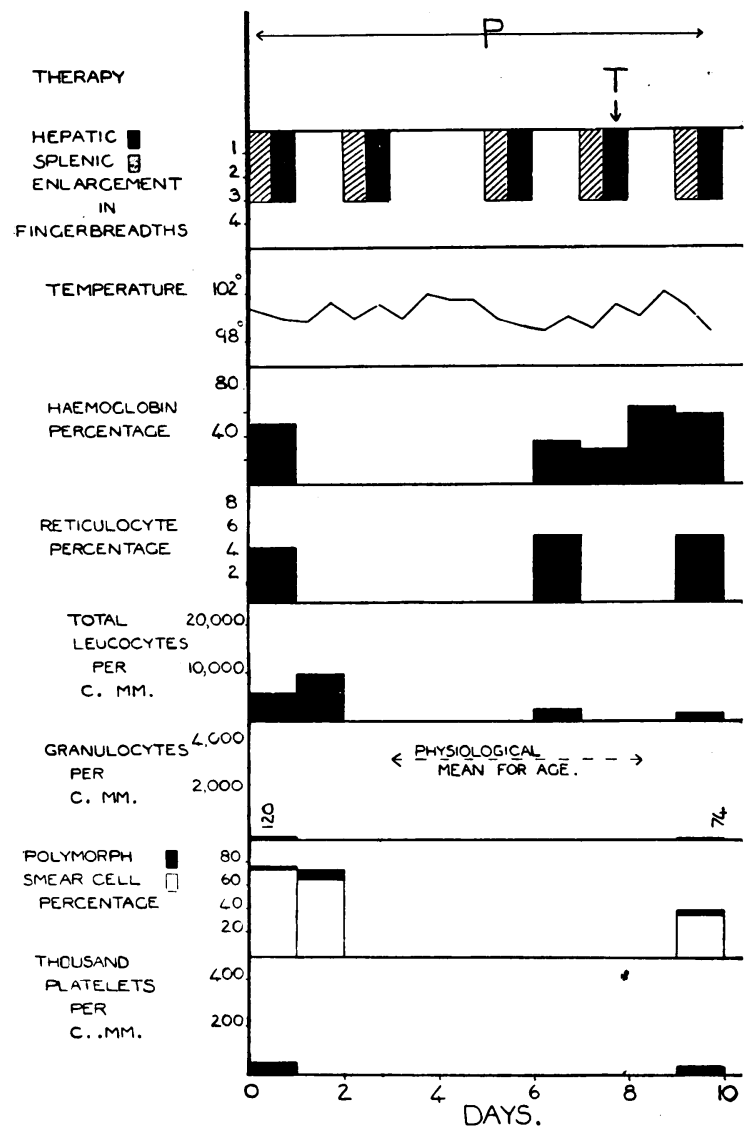

FIG. 1.-Clinical record of Case 1.

was of no value in arresting the downhill progress, and the baby died on the tenth day in hospital and the twenty-first day of his illness.

NeCROPSY REPORT. The body was that of a large male child weighing $13 \mathrm{lb}$. It was very jaundiced. The abdomen was greatly distended and large ecchymoses were present.

The brain was not abnormal apart from some diffuse yellow staining of the cerebral and cerebellar cortex. In the thorax there was evidence of terminal aspiration of gastric mucus. The lungs were healthy and the heart not abnormal. The abdomen was somewhat distended and the liver large with a smooth capsule. On section the organ was a peculiar bluish green, and some yellow flecks were noted.

The spleen was greatly enlarged, firm and dark red, while section revealed congestion.

The biliary system was normal. Apart from a few petechial haemorrhages over the kidney surface, the urinary tract appeared healthy. The marrow in the mid shaft of the femur was highly reactive.
Microscopical RePORT. The capsule of the liver was normal. The liver cells showed post-mortem change, but in addition there were areas of central and portal zone necrosis and there was widespread fatty degeneration affecting all zones of the lobules. In the necrotic areas only the outline of liver cells remained and there was some inflammatory cell infiltration. These cells were mainly lymphocytes and plasma cells but a few polymorphonuclear leucocytes were also present. The cellular infiltration was most pronounced in the portal tracts. There was considerable postmortem invasion by bacteria so that it was difficult to assess the degree of ante-mortem necrosis.

The capsule and trabeculae of the spleen were little affected. The pulp showed severe post-mortem change. It had been intensely congested, but the majority of red cells had become lysed. The Malpighian bodies were still recognizable but they, too, had undergone postmortem change.

The bone marrow was highly reactive. The reaction was normoblastic in character. Some post-mortem change had occurred.

Nothing of relevant importance was noted in the heart, lungs, kidneys or brain and these findings did not explain the clinical picture of a progressive panhaematopenia despite a highly reactive marrow. It was considered possible that the maturation of all elements of the marrow had been inhibited by either primary or secondary functional hypersplenism and that this influence had been effective in preventing immature cells from spilling out in greater numbers into the peripheral blood.

Case 2. Rachael was born to the same parents in the following year. Pregnancy had been uncomplicated, and delivery of the baby, who weighed $7 \mathrm{lb}$. $6 \mathrm{oz}$., was spontaneous. She appeared well at birth, was not jaundiced and fed eagerly from the breast, gaining 4 to 6 oz. weekly.

Five days before admission, when 9 weeks old, she had a few loose stools and then three days later she vomited, was listless and fretful and 'looked sunburnt'.

The vague but almost identical symptomatology, which had heralded the fatal illness of the first child, occurring at exactly the same age in weeks, disturbed the parents and they brought the baby to hospital. Preliminary examination revealed a clinical picture closely resembling that of the deceased sibling.

The infant weighed $10 \mathrm{lb} .6 \mathrm{oz}$., was febrile and peevish and the skin had the same sunburnt appearance. Both liver and spleen were enlarged to two fingerbreadths below the costal margin, but again lymph node enlargement was not noted. The haematological findings, the enlargement of the spleen and liver and the daily temperature, with the therapy, are recorded in Fig. 2. Once again, the differential blood film was characterized by scanty numbers of granulocytes and a varying percentage of smear cells. It was not possible to make films without damaging these cells, and although they frequently varied in inverse proportion to the granulocytes they more closely resembled the lymphoid series. Marrow was obtained with ease from the tibia repeatedly 
during the illness and in more than usual abundance. The myelograms will not be reported in detail as the reports were fairly consistent and described a brisk leucoand erythroblastic reaction, at times with a preponderance of lymphocytes. No other abnormality was noted. Red cell fragility was normal. The Wassermann and Kahn tests and the tuberculin reaction were negative. The serum cephalin cholesterol test was +++ , the thymol turbidity 4 units and the serum alkaline phosphatase 20 King units $\%$. No abnormality was noted in the total serum protein, a l bu min - globulin ratio, blood urea nitrogen, serum chloride, serum sodium and potassium, serum phos-. phorus and bilirubin levels.

The blood group was $\mathrm{O}$ Rh positive, and the Coombs test was positive.

Radiological examination of the chest, abdomen and bony skeleton only served to confirm the enlargement of liver and spleen.

The baby proved to have a poor appetite and tubefeeding was at times necessary while at others the diet had to be reduced to Ringer-lactate solution on account of loose and offensive stools. The periodic bouts of pyrexia-the temperature never really settled-received treatment with penicillin, chloramphenicol or aureomycin, but without any obviously related good effect. Between the fifteenth and eighteenth days after admission the granulocytes fell to their lowest absolute level, large numbers of smear cells appeared, and the spleen, which had temporarily receded, again increased in size. The haemoglobin fell a little as did the reticulocytes although there was no consistent relationship between these two. It was decided, in view of the possibility of hypersplenism and the reputed anti-splenic action of A.C.T.H., to give this versatile substance a trial. A.C.T.H. therapy was begun on the twenty-first day in doses of 


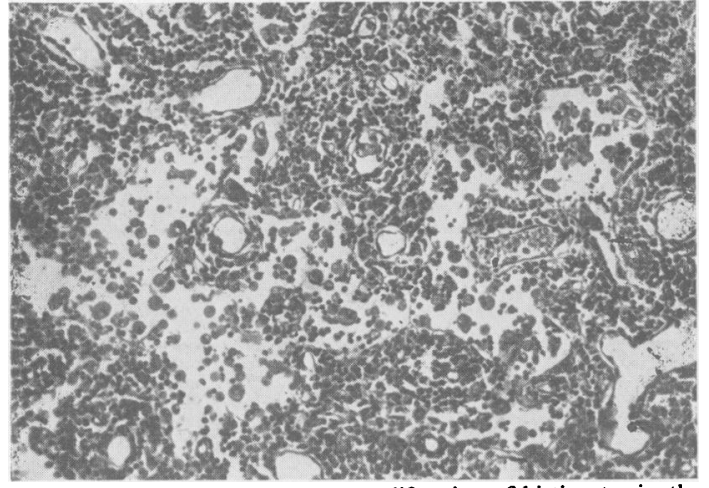

FIG. 3.-Lymph node showing proliferation of histiocytes in the sinuses. Haematoxylin and eosin. $\times 100$.

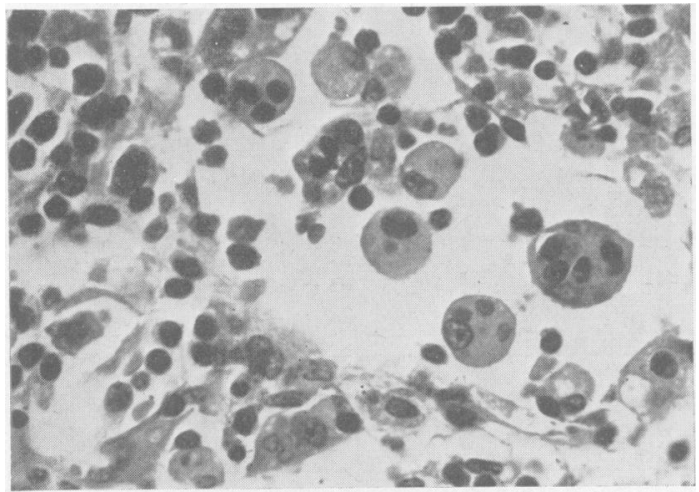

FIG. 4.-Histiocytes in sinus of a lymph node showing phagocytosis of red cells and white cells. Haematoxylin and eosin. $\times 500$.

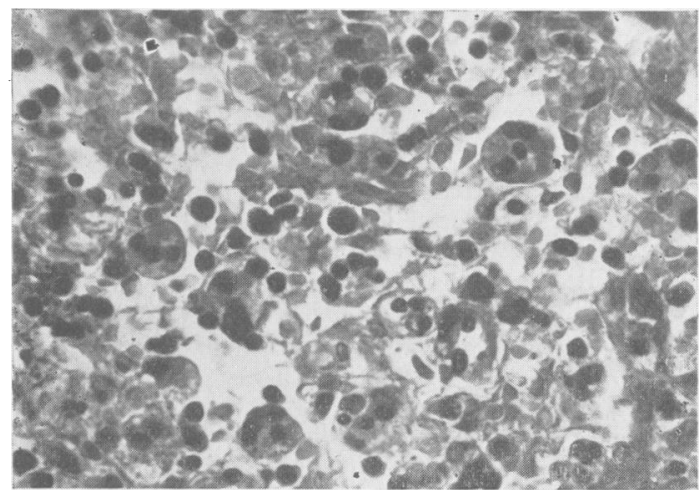

FIG. 5.-Numerous histiocytes showing haemophagocytosis in the splenic pulp. Haematoxylin and eosin. $\times 425$.

drop in the granulocytes necessitated the addition of a further $5 \mathrm{mg}$. to the dosage. Despite this, the general condition continued to deteriorate. The baby had a high remittent temperature for which no explanation could be found; the liver and spleen rapidly enlarged, the skin became more 'sunburnt' although there was no rise in the serum bilirubin level and some purpura was noted; the haemoglobin, absolute granulocyte and platelet counts fell despite a richly reactive marrow; nucleated red cells were numerous in the peripheral blood (33 per 100 white cells), there were many polychromasic cells and a few large immature cells, which were classed as lymphocytes, appeared.

The baby died on the twenty-fourth day of her second admission in the ninety-fourth day of her illness.

NECROPSY REPORT. The body was that of a fairly well developed,' but extremely pale, female infant, weighing $12 \mathrm{lb} .11 \mathrm{oz}$. The abdomen was greatly distended. The examination was limited to an abdominal incision.

The liver was enlarged and pale on section. Splenomegaly was present and on section the organ was dark red. The renal cortex and medulla were found to be very pale.

The mesenteric and para-aortic lymph nodes were reddish-pink and slightly enlarged. The marrow was red and reactive.

No other abnormality was noted.

MICROSCOPICAL REPORT. There was a considerable alteration in the architecture of the mesenteric lymph nodes as the result of an extensive proliferation of the littoral cells in the sinuses (Fig. 3). The follicles were small and the sinuses were packed with histiocytes and prehistiocytes, which varied in size from $10 \mu$ to $25 \mu$. They had an oval or horseshoe-shaped nucleus and an acidophil cytoplasm. They were actively phagocytic and many contained one or more red cells, lymphocytes. and even polymorphonuclear leucocytes (Fig. 4). In a few cases the red cells had been destroyed and haemosiderin granules were present in the histiocytes.

The capsule and trabeculae of the spleen were normal. The pulp was intensely engorged and packed with erythrocytes. The Malphighian bodies were poorly developed. Some were very small and a number of arterioles lacked a lymphocytic sheath. In the pulp there was a great proliferation of histiocytes (Fig. 5). Many of these showed erythrophagocytosis and others contained lymphocytes and polymorphs. There was slight haemosiderosis.

The capsule of the liver was normal. The liver cells in the portal zones of the lobules showed slight fatty degeneration. There was very extensive infiltration of the portal tracts and periportal zones by histiocytes, lymphocytes, reticulum cells and plasma cells (Fig. 6). In addition there was widespread proliferation of the histiocytes throughout the liver sinusoids where they had probably arisen from Kupffer cells. The histiocytes were actively phagocytic and contained red cells, lymphocy tes and polymorphs (Fig. 7).

In the kidneys focal collections of cellular infiltration were noted in the cortex around a number of glomeruli. The cells were chiefly reticulum cells and lymphocytes, but large histiocytes were also present.

Sections of lumbar vertebrae were examined. The marrow was reactive and very cellular. There was a tremendous proliferation of acidophil histiocytes. These cells showed great phagocytic activity and were ingesting red cells, lymphocytes and polymorphonuclear 
leucocytes (Fig. 8). There was considerable normoblastic erythropoiesis and granulopoiesis was also in progress.

After these interesting histological findings the sections from the previous child were examined again.

Addendum to Microscopical Report (CASE 1). The capsule and trabeculae of the spleen were normal. The pulp was engorged but most of the red cells had become lysed as a result of post-mortem change. The Malpighian bodies were poorly developed and rather small. A number of arterioles lacked a lymphocytic sheath. There were large numbers of acidophil histiocytes throughout the pulp and many contained lysed erythrocytes and disintegrating polymorphonuclear leucocytes.

There was considerable histiocytic proliferation in the sinuses of the lymph nodes and many of the histiocytes showed phagocytosis of red cells and polymorphs. There was much post-mortem change.

Post-mortem change in the bone marrow was severe, but numerous histiocytes could be made out and they were seen to contain red cells.

There was moderate infiltration of the interstitial tissue of the kidneys with histiocytes.

The capsule of the liver was normal. The organ had undergone considerable post-mortem change. The portal tracts showed heavy infiltration with lymphocytes and histiocytes. The liver cells in the portal zones of the lobules showed fatty degeneration. Numerous histiocytes were also present in the sinusoids.

Case 3. Although warned that further children might be similarly affected, the parents permitted another pregnancy. The mother remained well but anxious throughout, showed no evidence of $\mathrm{Rh}$ sensitization, and in August, 1952, a girl was born.

This infant's progress has since been followed by one of us (J.W.F.). No abnormality was noted at birth apart from an increased number of smear cells in the peripheral blood. She was thereafter examined clinically, haematologically and serologically at intervals of six weeks. Enlargement of the lymph glands was noted at two weeks but quickly resolved. The percentage of smear cells fell but did not disappear and serological examination remained negative till the age of 8 weeks. At this point a trace of cold agglutinins appeared in the blood and also $33.5 \%$ of cells, the nature of which could not be accurately defined. Dr. A. R. Macgregor reported on the film as follows:

' The large mononuclears are cells that might be small monocytes or atypical large lymphocytes. They have pale cytoplasm and a nucleus that is often distorted and flattened so that identification is difficult. Their large number is an unusual feature of the films.'

At 10 weeks the parents brought the child to hospital because of sudden marked anorexia and the mother feared that the complexion was assuming the character noted in the two affected siblings. This latter sign was doubtful and although palpable the liver was not considered to be enlarged while the spleen was not palpable. The haemoglobin had fallen somewhat and the peculiar cells in the peripheral blood persisted. More strikingly,

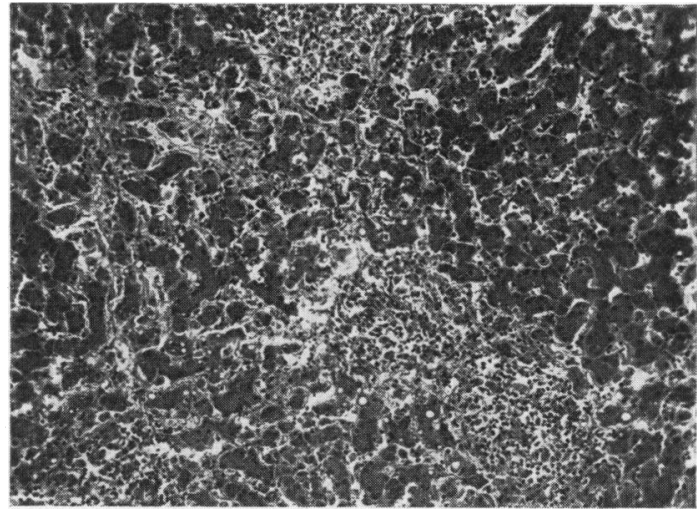

FIG. 6.-Pronounced cellular proliferation in the portal tracts of the liver. Haematoxylin and eosin. $\times 80$.

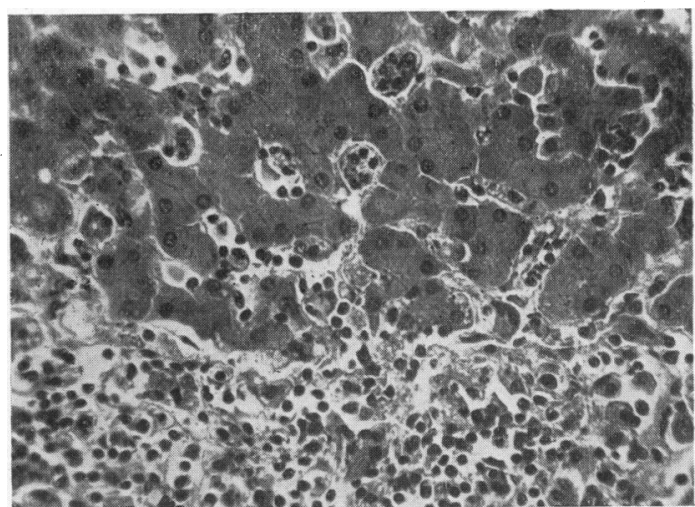

FIG. 7.-Infiltration of portal tracts with histiocytes, reticulum cells, lymphocytes and plasma cells. Histiocytes in the sinusoids show haemophagocytosis. Haematoxylin and eosin. $\times 280$.

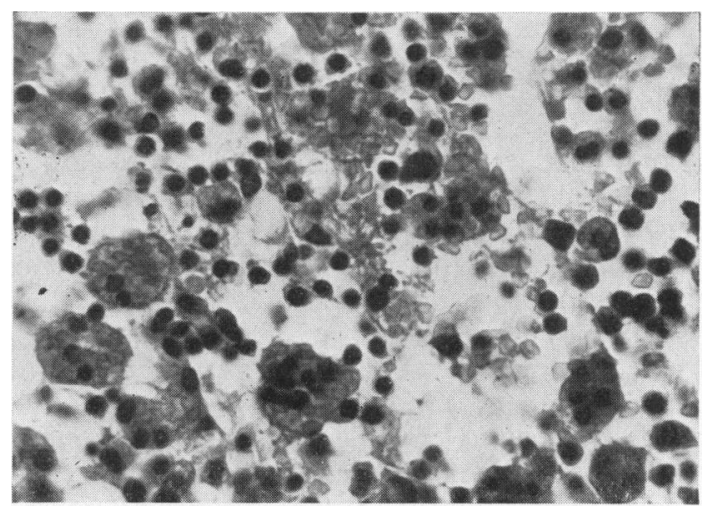

Fig. 8. - Large histiocytes in the bone marrow full of red cells and white cells. Haematoxylin and eosin. $\times 450$

however, the Coombs test had become undoubtedly positive. The anorexia, the falling haemoglobin, the presence of smear and other atypical cells with the finding first of cold agglutinins, and then a positive Coombs test at the eighth and tenth weeks are ominous. The case will continue to be followed and reported later should the diagnosis be confirmed. 
Discussion

During the second child's illness a detailed family history of four generations was obtained, and although the families were large, few deaths had occurred in infancy and of these the cause was unknown to the available witness in two cases only. In the others death could not be suspected as being due to familial haemophagocytic reticulosis from the available history.

The positive direct Coombs test in the second infant was also made the subject of further investigation. Her blood group was $\mathrm{O} \mathrm{R}_{\mathrm{I}} \mathrm{r}(\mathrm{CDe} / \mathrm{cde})$, and her father, who was $\mathrm{O} \mathrm{R}_{2} \mathrm{r}$ (cDE/cde), also had a positive direct Coombs test which was confirmed at the Lister Institute. The mother was $O R_{I} r$ $(\mathrm{CDe} / \mathrm{cde})$ and no abnormal antibodies against a wide range of known blood groups (MNS,' $P$, Lewis, Lutheran, Kell, Duffy and Kidd) could be distinguished in her blood. It was decided to follow up the paternal side of the family, and the grandfather was found to be group $\mathbf{O} R_{\mathbf{I}} R_{\mathbf{I}}$ $(\mathrm{CDe} / \mathrm{CDe})$ with a negative direct Coombs test. The grandmother, who was a robust woman of late middle age, was found to be group $\mathrm{O} \mathrm{rr}$ (cde/cde). Her direct Coombs test was probably negative and was ruled as being so by Dr. Mourant at the Lister Institute, but Dr. Cumming noted an atypical clumping of cells, which could be dispersed by agitation, such as he had observed previously in cases of haemolytic anaemia. These findings. were not explained, but it was considered feasible that the disordered reticulo-endothelial system was responsible for the abnormal antibody. The fact that the direct Coombs test had been reported as negative in the first baby was against this, but a link was provided by this strange finding between the second child and the paternal side of the family. Another interesting feature was the discrepancy between the $\mathrm{Rh}$ genotyping of the grandparents and their child, either the genotyping being incorrect or else there were ramifications of the family stock not incorporated in the official pedigree. This latter finding leaves open the possibility that an abnormal gene was introduced at this point.

The parents of the children were subjected to physical and haematological examination, but all that could be found was a muddy pallor of the skin in the father whose haemoglobin was estimated at the low level for a male of $86 \%$, despite the fact that his diet was satisfactory; there was no obvious blood loss and he was an energetic and successful Association footballer. It was thought unlikely that marrow puncture would aid further in his assessment as it had not provided the clue in the children. In haemophagocytic reticulosis and in
Letterer-Siwe disease there is a tremendous increa se in the number of histiocytes in the bone marrow at the expense of the blood-forming cells. This histiocytic proliferation probably increases the cohesion of the marrow and renders aspiration more difficult. It was not found possible to carry out splenic puncture, lymph node biopsy, or marrow trephine.

In the children histological examination revealed lesions in the lymph nodes, spleen, liver, bone marrow and to a lesser extent in the kidneys.

The condition is a reticulosis. This takes the form chiefly of a tremendous overgrowth of histiocytes, but reticulum cells, lymphocytes and plasma cells are also found, particularly in the medulla of lymph nodes and in the portal tracts of the liver.

Once the pathology is known the clinical picture is readily understood. In response to the histiocytic phagocytosis of the blood cells in lymph nodes, marrow, liver and spleen the marrow attempts to compensate by brisk haematopoiesis. It may be that the abnormal process is present at birth, but that at that stage the marrow and extra-medullary centres are capable of holding the balance. By 9 weeks of age, however, in both cases the destructive process preponderated although there was some cyclical remission and relapse in Case 2, and terminally in both cases the marrow was unable to cope with the progressive destruction and progressive panhaemotopenia. Estren and Dameshek (1947) and Dameshek and Estren (1950) believe that the spleen normally exerts an influence on the marrow designed to prevent the escape of immature cells into the peripheral blood, and when this is excessive inhibition of the marrow may follow with a progressive deficiency of one or more cellular elements in the blood stream. Such functional hypersplenism may be not only primary but secondary to other disorders causing splenomegaly. Should this be so, then the destructive process in haemophagocytic reticulosis alone may not be responsible for the full clinical picture, but the marrow, although apparently hyperplastic may be partially arrested and its capacity to compensate hampered. If it were to have been removed in these cases more immature cells of both the red and white series might have been released into the peripheral blood.

In the second child there appeared to have been at least one partial remission possibly associated with the giving of A.C.T.H. From the graphical records (Figs. 1 and 2) it is not possible to correlate closely the variations in hepatosplenomegaly with the peripheral blood findings, because the former is but a measure of the destructive process and gives no indication of the compensatory haematopoiesis.

The jaundice in the first case was probably partly 
haemolytic and partly due to hepatic dysfunction. Even when the serum bilirubin level was normal, each case presented a peculiar sunburnt appearance of the skin which could not be explained as either racial pigment or due to exposure to sunlight.

The terminal skin petechiae undoubtedly represented the active phagocytosis of platelets and resultant thrombocytopenia.

Letterer-Siwe's disease has become synonymous with non-lipoid reticulosis and reticuloendotheliosis. Haemophagocytic reticulosis is a non-lipoid reticulosis occurring in young infants but it differs in many respects from Letterer-Siwe disease. In the first place, haemophagocytic reticulosis is a familial condition. Siwe (1933) in listing his criteria for the diagnosis of non-lipoid reticuloendotheliosis states that 'the disease is neither hereditary nor familial '. Recently Reese and Levy (1951) have described a 'familial incidence of non-lipoid reticuloendotheliosis (Letterer-Siwe disease)', but we suggest that their cases may actually have been examples of familial haemophagocytic reticulosis although the post-mortem marrow was not typical. As Claireaux and Lewis (1950) pointed out, the basic pathological lesion in Letterer-Siwe disease is a granuloma composed chiefly of histiocytes. In haemophagocytic reticulosis, on the other hand, the cellular infiltrations are diffuse in character and the proliferating histiocytes do not group themselves in the form of granulomata. Haemophagocytosis is not a feature of Letterer-Siwe disease and bone defects do not occur in familial haemophagocytic reticulosis.

Physiological erythrophagocytosis occurs in the sequestration and destruction of old cells by the spleen, and pathologically when the red cell is abnormal as in congenital haemolytic anaemia. It is just possible that the basic abnormality in this condition is indeed in the red cell and that reticuloendothelial hyperplasia is a response to it, white cells and platelets being engulfed pari passu with the erythocytes. On the other hand, the reticuloendothelial system may be primarily pathological as suggested in the cases of hypersplenism described by Doan and Wright (1946) and Doan (1949).

The cases of splenic haematopenia present with acute or chronic selective sequestration and destruction of red cells (Doan, Curtis and Wiseman, 1935), platelets (Wiseman, Doan and Wilson, 1940) or granulocytes (Wiseman and Doan, 1942) associated with hyperplasia of highly phagocytic reticuloendothelial cells with or without splenic enlargement. Doan (1949) points out, however, that the spleen generally mirrors the reticulo-endothelial system as a whole and that similar phagocytes are present in the liver, marrow, lymph nodes and diffuse con- nective tissue. In such cases accelerated splenic destruction of one or more cellular elements of the blood is accompanied, as in haemophagocytic reticulosis, by maximum marrow hyperplasia. This hyper-instability of the spleen may be one of the primary factors in congenital haemolytic anaemia where it may be inherited as a Mendelian dominant and at other times, where direct inheritance is difficult to establish, as a recessive. This direct inheritance of abnormal reticulo-endothelial function is also apparent in our two cases.

Splenectomy has been found successful in the treatment of splenic haematopenia (Doan, 1949), but he records two cases in which it failed and where a generalized reticulo-endothelial hyperplasia and hyperphagocytosis was found in association with a reactive marrow and where the liver, lymph nodes, marrow and connective tissue participated sufficiently to render ineffective the removal of the splenic phagocytes. It may be that such cases occupy a position somewhere between the physiological and the trend toward haemophagocytic reticulosis. The latter has certainly a widespread pathology. The cause of the histiocytic proliferation is unknown and treatment is of no avail.

\section{Summary}

Two fatal cases of haemophagocytic reticulosis occurring in infancy are described in siblings. This designation is preferred for certain reasons to that of histiocytic medullary reticulosis. Interesting familial serological findings are recorded. The clinical and pathological features are correlated and the relation of this rare condition to other disorders of the reticulo-endothelial system discussed.

We wish to express our gratitude to Professor R. W. B. Ellis and Dr. A. R. Macgregor for their advice and to the former for permission to publish these cases; to Dr. R. A. Cumming, Director of the S.E. Scotland Blood Transfusion Service, for the serological findings, to the biochemistry and pathology laboratories of the Royal Edinburgh Hospital for Sick Children for the technical investigations and to the house physicians for their careful records.

\section{BIBLIOGRAPHY}

Anderson, R. G. (1944). Brit. med. J., 1, 220.

Asher, R. (1946). Lancet, 1, 650.

Claireaux, A. E. and Lewis, I. C. (1950). Archives of Disease in Childhood, 25, 142.

Dameshek, W. and Éstren, S. (1950). Med. Clin. N. Amer., 34, 1271

Doan, C. A. (1949). Bull. N.Y. Acad. Med., 25, 625 .
, Curtis, G. M. and Wiseman, B. K. (1935). J. Amer. med. Ass., $105,1567$.

- and Wright, C. S. (1946). Blood, 1, 10.

Estren, S. and Dameshek, W. (1947). Amer. J. Dis. Child., 73, 671

Reese, A. J. M. and Levy, E. (1951). Archives of Disease in Childhood. 26, 578.

Robb-Smith, A. H. T. (1938). J. Path. Bact., 47, 457.

Siwe, S. A. (1933). Z. Kinderheilk., 55, 212.

Scott, R. B. and Robb-Smith, A. H. T. (1939). Lancet, $2,194$.

Wiseman, B. K. and Doan, C. A. (1942). Ann. intern. Med, 16, 1097 $\longrightarrow$, and Wilson, S. J. (1940). J. Amer. med. Ass. 115, 8. 